\title{
Social class and reinforcer effects in discrimination learning'
}

\section{BETTY JO MCGRADE, ${ }^{2}$ CAMBRIDGE, England}

Lower-class and middle-class English boys learned a size discrimination under four reinforcement conditions: (a) signal light, (b) candy, (c) "right, correct", and (d) "good, fine." The signal light and candy conditions required fewer trials to criterion than the verbal conditions. Neither social class nor the interaction between social class and reinforcers was significant.

Terrell, Durkin, \& Wiesley (1959) have reported that reinforcer effectiveness is a function of Ss' social class background. Using a signal light in one condition and light plus candy in another, they found middle-class children more responsive to light alone while lower-class Ss learned more quickly with candy. In a later study using two types of verbal reinforcers, Zigler \& Kanzer (1962) also found an interaction with social class. Lower-class Ss were more influenced by "good" and "fine" while middle-class Ss were more responsive to "right" and "correct." Zigler and Kanzer suggested that their "right-correct" condition was analogous to a signal light furnishing knowledge of results, while "good-fine" conveyed approval, a direct reinforcer similar to candy. The present study used these four reinforcer conditions to investigate the similarity suggested.

Two recent studies have failed to replicate the interaction reported by Zigler and Kanzer (Rosenhan \& Greenwald, 1965; McGrade, 1966) and with a broad range of incentives, Witryol, Tyrrell, \& Lowden (1965) have found few social class effects. Since no replication of Terrell et al has been reported, the present study follows their general procedure. One change was the present study's use of a naive $E$, who had been thoroughly trained in the experimental procedure but did not know the hypotheses under study.

Method

The Ss were 80 boys, seven and eight years old, attending state supported schools in Cambridge, England. Half were supplied by a school in a heavily working-class neighborhood. The remainder came from an upper-middle-class area.

The "game" consisted of a wooden box, $18 \times 12 \times 5$ in., and a stand 10 in. tall on which was mounted a red light bulb. When light was to be the reinforcer, this stand was placed immediately behind the box and wired to two pairs of permanently mounted push buttons: one pair on the top surface of the box accessible to Ss and a second pair on the back visible only to $E$. The stimuli were three-dimensional shapes, triangular prisms and rectangular prisms, each in two sizes, with sides $1-1 / 4 \times 5 / 8$ or $2-1 / 2 \times 1-1 / 4$ in.

One woman $E$ was used. After bringing the child to the experimental room, she said: "I'm going to put two blocks up on this box. You pick one and push the button in front of the block you've chosen." In the light condition only, she continued, "If you pick the correct one, this light will go on." After the first trial, E said: "Now I'll put up two more and you choose again."

On each trial a small and a large block of the same shape were presented. Alternate Ss were reinforced for choosing the large block or the small. The order of presentation randomized the occurrence of triangles and rectangles over trials and the position of large and small blocks on the left or right. Every correct response was reinforced to a criterion of 9 out of 10 correct, or until the $S$ had made 60 responses. In verbal conditions, the two words were used alternately. For candy reinforcement, E placed a single $M$ \& $M$ on the table near $S$ with no verbal comment. In

\begin{tabular}{llcccr} 
& \multicolumn{5}{c}{$\begin{array}{c}\text { Table 1 } \\
\text { Mean Trials to Criterion } \\
\mathbf{N}=\mathbf{1 0} \text { per Cell }\end{array}$} \\
\hline Social & & light & \multicolumn{3}{c}{ Reinforcement conditions } \\
right-correct & good-fine & candy \\
Class & middle & 17.1 & 32.5 & 33.5 & 21.2 \\
Groups & lower & 22.5 & 36.9 & 35.8 & 29.4 \\
\hline
\end{tabular}

the light condition, the bulb went on automatically when S pushed a button corresponding to one $E$ depressed behind the box.

Results and Discussion

The dependent variable was trials to criterion, and mean scores for the groups on this measure are shown in Table 1. An analysis of variance was performed on these scores, two social classes by four reinforcement conditions. Only the $F$ for reinforcement conditions approached significance $(F=2.20, \mathrm{df}=3 / 72, \mathrm{p}<.10$ ). Comparisons among the reinforcement conditions showed a significant dichotomy between the two verbal reinforcers on one hand and light and candy on the other $(F=5.99$, df $=1 / 72, p<$ $.025)$. The suggested dichotomy, light and right-correct vs goodfine and candy, was insignificant $(F<1)$. The residual from these two orthogonal comparisons was also insignificant $(F<1)$.

Scores for the four reinforcement conditions fail to support Zigler and Kanzer's suggestion that "right-correct" functions like a signal light, "good-fine" like candy. The present results can be handled more easily by a distinction between verbal and nonverbal reinforcers, and agree with a previous report that the non-verbal are more effective at this age level (Witryol et al, 1965).

These data show no indication of the social class by reinforcer interaction reported by Terrell et al. The major difference in procedure between studies is the use, by Terrell et al, of a signal light with its accompanying instructions in all conditions, while the present study separated light and candy. It is, however, difficult to see why reducing the overlap between conditions should eliminate this interaction. Possibly English boys are different from their American counterparts in some way which accounts for the negative finding, or the use of a naive $E$ may be crucial, but at least the present results suggest limitations on the generality of previously reported social class by reinforcer interactions.

\section{REFERENCES}

MCGRADE, B. J. Effectiveness of verbal reinforcers in relation to age and social class. J. Pers soc. Psychol, 1966, 4, 555-560.

ROSENHAN, D., \& GREENWALD, J. A. The effects of age, sex and socioeconomic class on responsiveness to two classes of verbal reinforcement. J. Pers, 1965, 33, 108-121.

TERRELL, G., DURKIN, K., \& WIESLEY, M. Social class and the nature of the incentive in discrimination learning. J. abnorm. soc. Psychol., 1959, 59, 270-272.

WITRYOL, S. L., TYRRELL, D., \& LOWDEN, L. Development of incentive values in childhood. Genet. Psychol. Monogr., 1965, 72, 201-246.

ZIGLER, E., \& KANZER, P. The effectiveness of verbal reinforcers on the performance of middle- and lower-class children. J. Pers, 1962, 30, $157-163$.

1. The author is indebted to the late Michael Blake, of the Medical Research Council, Applied Psychology Research Unit, Cambridge, for his assistance during this study, and to Ruth Blake, who served as experimenter. The kind cooperation of the headmasters, teachers and students of St. Luke's School and Newnham Croft School is gratefully acknowledged.

2. Address: 31 Paton St., Cambridge, England. 